\title{
Stockholm University
}

This is a published version of a paper published in Journal of Indian Philosophy.

Citation for the published paper:

Oetke, C. (2013)

"A Brief Appraisal of the Sadvitiyaprayoga"

Journal of Indian Philosophy, 41(1): 43-55

Access to the published version may require subscription.

Permanent link to this version:

http://urn.kb.se/resolve?urn=urn:nbn:se:su:diva-92825

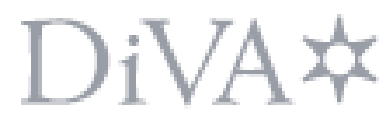

http://su.diva-portal.org 


\title{
A Brief Appraisal of the Sadvitīyaprayoga
}

\author{
Claus Oetke
}

Published online: 12 February 2013

(C) Springer Science+Business Media Dordrecht 2013

A short piece of argumentative reasoning that was supposedly advanced by advocates of 'non-orthodox' materialist teachings has been preserved which will be referred to by the term sadvitīyaprayoga. Remarks about this topic can be found in different articles, and in a recently published paper with the title 'A Note on the Sadvitiyaprayoga' (Franco 2012) E. Franco has advocated an explanation of this argument and contrasted it with previous interpretations. In the following paragraphs I will confine myself to briefly sketching an account exhibiting points of agreement and points of disagreement with respect to earlier analyses.

The so-called sadvitīyaprayoga, which reads

abhivyaktacaitanyaśarīralakșaṇapuruṣaghațānyatarasadvitīyo ghațh, anutpalatvāt, kuḍavat

[The] pot possesses a counterpart either in the form of a man characterizable as a body where consciousness is manifested or in the form of [the/a] pot because it is not a lotus, like a wall.

is presumably directed against a form of argument which consists in an extrapolation from otherwise effective regularities to a particular case in point. This means, couched in technical terms of theory of anumāna, its target is the conclusion that some particular object functioning as the paksa in a pertinent inference must exhibit a particular sādhya-property given (1) that it in fact exhibits a particular hetu-property and (2) in the realm of all (existing) objects different from the pakșa it holds good without any exception that things exhibit the sādhyaproperty whenever they exhibit the hetu-property. It is easy to verify that the two mentioned requirements are satisfied in the pertinent case: On the one hand it appears hardly deniable that a pot is not a lotus, that a pot exhibits the property of

C. Oetke $(\bowtie)$

University of Stockholm, Stockholm, Sweden

e-mail: claus.oetke@orient.su.se 
not being a lotus. On the other hand it cannot be reasonably denied that all real objects in so far as they are neither a pot nor a lotus must possess (the/a) pot as a counterpart either in the sense of being different from some existing pot or the other or in the sense of belonging to the realm of all objects which constitutes the complement of the realm of all pots in general. Accordingly, presupposing an-intuitively plausible-form of 'disjunctive extension' not only all non-lotuses, but even all objects different from the pakșa need to exhibit the property of either possessing a pot as a counterpart or possessing a man characterizable as a body where consciousness is manifested as a counterpart. To be sure, given that a disjunctive property of this type complies with the rule that if it is exhibited by some object and one of the alternatives is not exhibited by it then the other alternative must be exemplified by the object in question, one could, on the basis of the consideration that the/a pot cannot possess the/a pot as a counterpart-either in the sense that an individual pot cannot be different from itself or belong to a realm different from the realm of all pots or in the sense that the realm of pots in general cannot exclude any individual pot or realm of pots from its range-deduce from the previously established facts that some man definable as a conscious body must exist as some counterpart of a pot or of the realm of all pots. Accordingly the existence of some man exhibiting the nature of a conscious body would follow which stands in opposition to the established doctrines of the non-materialists. It seems, nevertheless, improbable that the overriding aim of the sadvitiyaprayoga lay in establishing the truth of a materialist tenet, because, as pointed out in Franco (2012, p. 223), the proponent would commit a fallacy if he intended to establish this conclusion in the framework of principles licensed by doctrines of anumāna. The decisive point is that the reasoning could be easily counterbalanced by an analogous argument establishing precisely the opposite conclusion so that the proponent's argument would exhibit a fallacy that is designated by the technical term viruddhāvyabhicārin.

It is easy to see that any inference of the form

$\mathrm{p}$ is either $\mathrm{S}$ or $\mathrm{S}^{*}$ because $\mathrm{p}$ is $\mathrm{H}$

complies with the demand that outside the domain of the subject of inference, i.e. the paksa, the property functioning as reason (hetu) must be invariably connected with the property to be proven (sādhya) given (1) that the former one is exhibited both by the pakșa itself and some object(s) different from the pakșa and (2) either ' $S$ ' or ' $S^{*}$ ' stands for an attribute which must be exhibited by every object that is not identical with the paksa. This means that, if the first requirement is met and ' $\mathrm{S}$ ' is taken as standing for any property exhibited (at least) by all objects apart from the pakșa, it is with respect to the question of the satisfaction or the non-satisfaction of the pertinent demand absolutely irrelevant what attribute the other member of the disjunction, i.e. ' $\mathrm{S}^{*}$ ', is taken to stand for. Hence the initially mentioned example instantiates a general type which might be named sadvitīyaprayoga-type, thereby referring to the sort of inference which complies with the two above-specified constraints. It follows that, in principle, the pertinent requirement can be met by advancing any inference of the form

$\mathrm{p}$ is either (numerically) different from $\mathrm{p}$ or $\mathrm{S}^{*}$ because $\mathrm{p}$ is $\mathrm{H}$ 
where ' $\mathrm{H}$ ' represents an attribute which is (apart from the pakșa) exhibited by some object(s) differing from the paksa, no matter which term is chosen as a replacement of ' $\mathrm{S}^{*}$ '. This diagnosis entails the following consequence: If (i) it were acknowledged as a valid principle of extrapolation that whenever some object (or group of objects) exhibits a certain attribute $\mathrm{H}$, such that it holds good for all objects differing from it that everything exhibiting $\mathrm{H}$ exhibits some (other) attribute $\mathrm{S}$ it ought be assumed that the pertinent object(-group) exhibits the latter attribute, $\mathrm{S}$, and if (ii) it is admitted that a 'disjunctive' attribute can be exhibited by something only if at least one of its constituent attributes is exhibited by it, then with respect to the concerned object(-group) the exemplification of any arbitrary attribute can be derived by a valid form of reasoning. This in its turn implies that any arbitrary inference ${ }^{1}$ complying with acknowledged standards of correctness can be 'counterbalanced' by some equally valid argument establishing precisely the opposite of the original inference. Against the background of doctrines of inferential reasoning expounded in various textual sources the disjunctive character of the attribute invariably connected with the attribute which functions as the probans is most crucial. For if the disjunctive sādhya were replaced by any of the constituents either the invariable connection in the domain apart from the subject of inference, the paksa, would not be guaranteed or an argument results which exhibits the flaw of being internally inconsistent and therefore unsuited to function as a counterbalancing inference. If, in the original example the attribute of either possessing a counterpart in the form of a man characterizable as a body where consciousness is manifested or possessing a counterpart in the form of [the] pot were replaced by the attribute of possessing a counterpart in the form of a man characterizable as a body where consciousness is manifested any invariable connection between the property functioning as probans and the property functioning as the probandum could not be taken for granted because the advocates of non-materialistic views disagree with the contention that some man who is nothing but a conscious body exists. If, on the other hand, the disjunctive probandum were reduced to its second component an argument would result which tries to establish that the/a pot possesses the/a pot as counterpart which could be rejected as self-contradictory and therefore unsuited as a counterbalancing inference. For the same reason one cannot replace an inferential argument of the form

$\mathrm{p}$ is either (numerically) different from $\mathrm{p}$ or $\mathrm{S}^{*}$ because $\mathrm{p}$ is $\mathrm{H}$ by

$\mathrm{p}$ is (numerically) different from $\mathrm{p}$ because $\mathrm{p}$ is $\mathrm{H}$

despite the fact that it is guaranteed that in the entire domain apart from the subject of inference (the pakșa) everything that exhibits the attribute functioning as probans exhibits the attribute functioning as probandum. Hence the sadvitiyaprayoga can be considered as an ingenious demonstration of the fact that any arbitrary inferential proof relying on the above depicted principle of extrapolation is bound to fail,

\footnotetext{
${ }^{1}$ We presuppose that only inferences are at stake where the question of whether a pertinent item exhibits the sädhya-property or not is (still) an open issue.
} 
provided that (a) such arguments are never probative if they can be counterbalanced by some argument establishing the opposite conclusion with the help of the same principle of extrapolation and (b) the support for the assumption that an object can exhibit a disjunctive attribute only if it exhibits at least one of its constituent alternatives is far stronger than the support for the validity of the pertinent principle of extrapolation. As far as (a) is concerned it can be vindicated by textual evidence that the existence of a counterbalancing argument establishing an opposing consequence on the basis of identical principles of validity destroys the probative character of a piece of inferential reasoning. On the other hand, the very circumstance that the existence of a situation described by the technical term viruddhāvyabhicārin has been presented in certain textual sources, e.g. in the Nyāyapraveśa, as a factor that deprives particular inferences of their probative force indicates that it was not commonly recognized that every piece of reasoning can be invalidated by a counterbalancing argument. Hence it can be presumed that the sadvitīyaprayoga did not point out a fact that was commonplace in its historical context.

However, the sadvitiya-type possesses a potential of impairing the credibility of the above specified principle of extrapolation that exists even independent of its possible function as a principle generating counter-balancing arguments. For the mere fact is highly disconcerting that the attribution of arbitrary attributes is licensed by the presentation of a probans that is 'invariably connected' with a probandum in the entire domain outside the subject of inference, the pakșa, in combination with a plausible principle to the effect that the exemplification of a disjunctive property ('P1 or P2 or ....') necessitates the exemplification of some of the remaining member(s) of the disjunction ('P2 or ...') whenever a pertinent object does not exhibit some particular member of the disjunction (say, 'P1'). Thus, given that it is evident that a any arbitrary object cannot be numerically different from itself, the circumstance that some object ('o') possesses a property ('H') that certain other object(s) possess too-so that in the entire domain apart from the object concerned ('o') it must hold true that everything possessing this property ('H') must also be such that it is different from that object ('o') and a fortiori either different from it or exhibiting some property $S^{*}$-would license the conclusion that the object ('o') possesses $S^{*}$, no matter what ' $S^{*}$ ' is taken to stand for. From this circumstance one can draw only one plausible conclusion: The pertinent principle of extrapolation must be faulty, at least as long as it is not modified. It appears to be absolutely futile to speculate about the issue whether the advocate(s) of the sadvitīyaprayoga envisaged a criticism of inferences relying on the extrapolationprinciple by referring to counterbalancing pieces of reasoning or by considerations along the lines outlined above or even by both. The only result which we can-at the present state of knowledge-safely derive is that from a purely theoretical perspective the sadvitiyaprayoga is suited to establish the faultiness of a principle of extrapolation of the presently hypothesized variety. In addition, however, it can be equally assumed that the pertinent principle of extrapolation has been in fact acknowledged in a certain historical period, and it is by no means improbable that the sadvitiyaprayoga was developed at a time and in a milieu in which the validity of the principle was admitted or at least not been subjected to a fundamental 
criticism. Various textual sources where in the form of the Trairüpya-doctrine and other theoretical elements criteria for the acceptability of pieces of inferential reasoning are expounded intimate this consequence.

If this is true then raising the question of whether or not the advocates of the sadvitīyaprayoga attempted to establish a concomitance or a vyāpti-cf. Franco (2012, p. 221) — can be misleading. ${ }^{2}$ For in some sense at least, the postulate of an invariable concomitance should be satisfied by arguments of the sadvitiya-type, because they are designed to show that compliance with that demand in all knowable instances-i.e. instances where knowledge of whether or not the properties functioning as probans and probandum occur together is not precluded by the very fact that the situation of a genuine inference exists—cannot constitute a sufficient reason for validly establishing a consequence. Moreover, all speculations about the issue whether the advocate(s) of the sadvitiyaprayoga acknowledged items exemplifying the corresponding 'negative concomitance', the so-called vyatireka, and if so, which examples he or they 'had in mind' (cf. Franco 2012, p. 221f) are absolutely irrelevant. First it is not absolutely certain that the requirement of negative concomitance was always interpreted as involving the existence of items exhibiting the non-occurrence of both the properties functioning a probans and probandum in an inference or argument. From a theoretical perspective it would be even disadvantageous to burden the principle of extrapolation with a requirement of this kind. For the intuitive basis of this principle consists merely in the idea that if in the entire realm of objects that remains if one disregards a particular controversial case there is no single exception to the rule that everything that exhibits some $\mathrm{H}$ also exhibits some $\mathrm{S}$, one is entitled to 'extrapolate' this situation to the case in question, so that one is entitled to derive the consequence that something exhibits $\mathrm{S}$, given that it exhibits $\mathrm{H}$. This idea of a rule that is (almost) universally complied with does in itself not entail that items also exist which do not exhibit one or the other of the pertinent qualities. Such a demand is even suited to generate fatal problems whenever the exemplification of qualities should be established that are allegedly exhibited by all objects of the universe. But it is precisely the establishment of properties of this sort which plays a most prominent role in the exploitation of means of inferential reasoning in the field of metaphysics. It is indeed true that in the sadvitiyaprayoga, according to the presented analysis, the properties which function as a probandum must be qualities that are exhibited by all objects of the universe outside the so-called paksa. But if any metaphysician raised the objection that the reasoning presented by the proponent of a sadvitiya-type of argument is faulty because he cannot specify any specific object that exhibits lack of the probandum, the advocate of the sadvitiyaprayoga can validly retort that if this impossibility constituted a fatal flaw it would follow that only probanda are admissible which are not universally instantiated and that this consequence would deprive the metaphysician of the possibility of exploiting reasoning relying on extrapolation for establishing tenets which the metaphysician would like to validate.

\footnotetext{
2 The assertion that the proponents of the sadvitiyaprayoga did not presuppose that their example complies with vyāpti in a sense which is suggested in the works of Dharmakîrti is probably true, and presumably this is the intended import of the contention. But in another, equally important, sense of the term it seems false to say that the sadvitiya-argument should not comply with a requirement of vyapti.
} 
There cannot be any doubt that, Dharmakīti, for example, would act as an absolute fool, if he confronted the advocate of the sadvitīyaprayoga with this objection.

The critical potential of the sadvitiya-type rests precisely on the circumstance that it specifies a sādhya-property which is necessarily exhibited by all objects apart from the so-called paksa. Therefore it would be inappropriate to equate it with the argument mentioned in Franco (2012, p. 223), which reads:

Sound is permanent because it is either the pakșa or a sapakșa ${ }^{3}$

It seems that the gist of this argument would be preserved if it were presented by the formulation:

Sound is permanent because it is either sound or something which is permanent and not sound.

It is easy to see that in this inference the property functioning as probans, viz. being either sound or some permanent non-sound, must be exhibited by the subject of inference, given that it is sound itself. It is equally obvious that no counterexample can occur violating the rule that everything which is not sound and is either sound or some permanent non-sound is permanent. For it is trivial that anything, given that it is not sound and permanent, must be also permanent. But the circumstance that there is something which is not sound and permanent cannot be taken for granted from the outset. Only if it can be taken for granted that there are permanent objects a proponent could be entitled to derive from the circumstance that the quality of being either sound or a permanent non-sound is exhibited by the subject of inference as well as by at least one different permanent object the conclusion that sound is permanent. If the tenet that there are no permanent objects in the universe were embraced it would not hold true that there is some non-sound which is permanent. This means, that, technically, the satisfaction of the second condition of Trairupya could not be admitted on those premises. If it were supposed in accordance with the hypothesis advanced in Franco (2012, p. 223) that the pertinent argument had been designed (by adherents of the school of Mīmāmsā) with the aim to discredit the (Buddhist) doctrine of Trairüpya, the criticism must have been construed in a fairly awkward manner because the thesis that no permanent objects exist has been advocated by some, most notably by the Buddhists. To be sure, the present from of reasoning could be invoked for discrediting in a most plausible manner a counterinference which would read as follows:

Sound is impermanent because it is either sound or something which is impermanent and not sound.

It is, however, far from clear that there was ever any need to employ the argument for such a purpose. Is it probable that somebody advanced the hypothetically envisaged argument for establishing the impermanence of sound? It is obvious at any rate that both the initially presented reasoning and its counterpart are affected

\footnotetext{
3 The second occurrence of the definite article in the formulation appearing in the article:

Sound is permanent because it is either the pakșa or the sapakșa.

appears infelicitous and has been amended above.
} 
by a flaw which discredits them on an account which differs from the problematic nature of the extrapolation principle. The form of reasoning represented by the arguments under consideration is as follows:

$\mathrm{p}$ is $\mathrm{S}$ because either $\mathrm{p}=\mathrm{p}$ or $(\mathrm{p} \neq \mathrm{p}$ and $\mathrm{p}$ is $\mathrm{S})$

Here, as before, 'p' should be reminiscent of the technical term paksa and ' $\mathrm{S}$ ' of the expression sādhya designating the quality which functions as the probandum in an inferential argument. Now, it is not difficult to verify that a predicate of the form

$\mathrm{Ax} \rightarrow((\neg \mathrm{Ax} v(\mathrm{Ax} \& \mathrm{Fx})) \rightarrow \mathrm{Fx})$

If $x$ is $A$, then, if $x$ is either not $A$ or both $A$ and $F, x$ is $F$

is necessarily true of any arbitrary object, whereas a predicate of the form

$(\neg \mathrm{Ax} v(\mathrm{Ax} \& \mathrm{Fx})) \rightarrow \mathrm{Fx}$

If $\mathrm{x}$ is either not $\mathrm{A}$ or both $\mathrm{A}$ and $\mathrm{F}, \mathrm{x}$ is $\mathrm{F}$

need not hold true of every object. Its satisfaction is not guaranteed in particular for objects which are not A, those of which ' $\neg \mathrm{Ax}$ ' is true. As soon as we consider 'Ax' as a replacement for ' $\mathrm{x} \neq \mathrm{p}$ ', readable as ' $\mathrm{x}$ is (numerically) different from the pakș', and ' $\mathrm{Fx}$ ' as a replacement of a predicate representing the quality which functions as the probandum and recognize that ' $\neg \mathrm{Ax} v(\mathrm{Ax} \& \mathrm{Fx}$ )' corresponds to the quality functioning as the probans in the proofs under consideration, we are in a position to give the following assessment of the situation: The circumstance that the rule that everything exhibiting the probans exhibits the probandum too in the realm of objects differing from the subject of inference, the pakșa, is merely a consequence of the truism that everything is what it is, that ' $\mathrm{Fx} \rightarrow \mathrm{Fx}$ ' must be true of any arbitrary object. But the same truism cannot equally guarantee that the object that functions as the pakșa exhibits the sādhya-quality. For an analogous guarantee could be provided only if the first element in the disjunction would be replaced by a conjunction of the original element and the predicate representing the probandum, that means by a replacement of ' $\neg \mathrm{Ax}$ ' by ' $\neg \mathrm{Ax} \&$ Fx' representing either 'is (not not) sound and permanent' in the first case, i.e. in the argument attributed to an advocate of Mīmāmssā, or by 'is (not not) sound and impermanent' in the second case, i.e. in the hypothetical reasoning which might be presented by a Buddhist. But under those alternative circumstances the reasoning would exhibit an obvious petitio principii and it could be rejected on grounds which are akin to those which have been explicitly mentioned in the tradition as factors that render an argument fallacious. Therefore the example where the permanence of sound is derived from its property of being either the paksa or some sapakșa does not present a particularly convincing counterargument against the principle of extrapolation. For, even admitting that the inference complies with the demand that in the domain outside the paksa no exception to the rule that everything exhibiting the probans also exhibits the probandum can occur, it can be objected that in the pertinent case this compliance is merely an immediate consequence of the truism that everything is what it is, whereas the same truism does definitely not license the supposition that the subject of inference must exhibit the probandum too, given that it exhibits the probans. Hence it could be claimed that the example involves a particular 
'degenerated' variety of invariable concomitance for which it is essential that it is guaranteed for the domain apart from the pakș on a basis by which it can never be guaranteed for the pakșa itself. Thus it could be plausibly argued that the principle of extrapolation deserves to be exempted from such degenerated varieties of 'invariable concomitance' without losing its validity in all other cases. The argument-form of the sadvitiya-type provides a stronger argument against the extrapolation principle. Even in the special case of

$\mathrm{p}$ is either (numerically) different from $\mathrm{p}$ or $\mathrm{S}^{*}$ because $\mathrm{p}$ is $\mathrm{H}$

an appropriate choice of probans is needed to guarantee that (1) the subject of inference in fact exhibits the probans and (2) the probans and the probandum are exhibited by some object apart from the pakșa and in the realm apart from the pakșa everything exhibiting the probans also exhibits the probandum. If these conditions are given, the extrapolation principle can be employed for the ascription of any arbitrary property to the subject of inference even if that property is not observable in any other instance. It can be assumed, moreover, that the very idea of a pakșa as something that differs from a realm of other objects guarantees that there is some quality which pertains to the pakșa alone, possibly in the form of a unique combination of general features which no other object exemplifies. Accordingly there is always some complementary quality which must be exhibited by all other objects which differ from the pakșa without being exemplified by the pakșa itself. Therefore it must hold good with respect to any arbitrary substratum of inference that disjunctive qualities formed by this complementary quality and any arbitrary other quality exist which satisfy the requirement of occurring together with some probans exhibited by the pakșa and certain other object(s) and, since they are instantiated by all objects different from the paksa, are instantiated by all objects different from the pakșa that exemplify the probans. That for every object in an nonempty universe there is at least one feature which it shares with some other object can be equally taken for granted. Thus the need of finding some appropriate probans and probandum for an individual case and of presenting a suitable example of inference is in principle dispensable.

In this connection one can object that an attempt to discredit the extrapolation principle is implausible because it disregards the intuitive plausibility of this principle. Shouldn't we admit that if it were supposed that apart from some particular raven all ravens are black it must be supposed that the concerned raven is equally black, and so on? Even granting that conclusions which are derived with the help of the extrapolation-principle are ordinarily not propositions which follow from pertinent premises with strict necessity, isn't it eccentric to disclaim its relevance for the acquisition of knowledge? Such considerations could discredit the supposition that the sadvitizyaprayoga aimed at demonstrating the invalidity of the extrapolation principle but they need not do so. The history of thought provides various examples where views and principles had been rejected which were not only commonly accepted, but appear intuitively credible and might even deserve to be accepted. Probably the issue of the 'real intentions' lying behind the sadvitiyaprayoga possesses merely limited importance, if any at all. At any rate an inquiry of the objective suitability to cast doubt on the extrapolation principle is not to the same 
degree affected by the danger of eliciting spurious speculations about the psychological states of foreign subjects.

It seems indubitable that the sadvitīyaprayoga, as long as its content is interpreted in the manner proposed above, is objectively suited to demonstrate that universal compliance with some regularity in some realm cannot by itself yield a sufficient condition for assuming compliance with the same regularity in some different realm and that this holds good irrespective of the extension of the former realm, provided it does not embrace a totality of all (relevant) objects. This needs to be reconciled with the intuition that compliance with a regularity in a great number of cases should license the supposition that the same regularity exists in other realms too.

Despite the circumstance that in the previously discussed examples disjunctive predicates occur specifying properties functioning as probans or probanda, it is presumably inappropriate to invoke the idea that the complex character of qualities should play a pivotal role for the validity or non-validity of the extrapolation principle. First, the contention that the principle is sound exclusively for cases where non-complex qualities come into play, threatens to dismiss many common inferences, such as

The burglar has entered the villa either from the left side door or the cellar window behind because all other doors and windows were closed and no windows, doors or locks are broken.

Second, and this is more important, it is by no means clear what the difference between complex and non-complex qualities amounts to. Should one suppose that the expression 'nut-brown' designates a complex quality because it is a composite expression and because its meaning involves a comparison with certain objects? Or should we rather affirm that 'brown' denotes a complex quality because it merely amounts to a disjunction of 'dark-brown or nut-brown or light-brown or ...'? Moreover, if it were supposed that an inference like

This year the first snow will come in December because it occurs always in this month here.

might be licensed by a principle of extrapolation, it would be utterly odd to contend that the inference

This year the first snow will come either in November or December because it always occurs either in November or December here.

cannot be legitimated by the same principle because the pertinent example involves disjunctive properties. Therefore it would be utterly implausible to dismiss the relevance of the sadvitiyaprayoga merely on the ground that it brings complex qualities into play.

But wouldn't it be much more reasonable to suppose that a general regularity observable in some realm is apt to license the assumption that it will be complied with in some extended realm inasmuch as the general nature of the regularity supports the supposition that it is the consequence of some more universal rule or law as a hypothesis? This would mean that the mere fact that some regularity holds good without exception in some realm does not by itself legitimate the extrapolation 
but only in combination with its ability to render credibility to the hypothesis that this regularity is due to some more comprehensive rule or law.

Against this background, the doctrines that have been propounded by the Buddhist philosopher Dharmakīrti could be understood as an attempt to account for the problem that has been highlighted in the sadvitiyaprayoga. It is however questionable that Dharmakirti's treatment of the issue was fully adequate. For on the one hand it can be plausibly assumed that Dharmakirti correctly acknowledged the fact that mere 'statistical' compliance with a regularity in some realm is not by itself sufficient to justify its extrapolation and that this can be the case even if no exception to the regularity exists in the concerned realm. To be sure, the supposition that some statistical compliance is merely the outcome of a universal law between cause and effect can justify the claim that the regularity deserves to be extrapolated to a more comprehensive realm of objects. It can be moreover conceded that the distinctive feature of the sadvitiyaprayoga as well as of certain other examples obstructing the validity of extrapolation lies in the circumstance that statistical regularities come into play which do not at all support the hypothesis that they are the result of some universal relation of cause and effect or some similar underlying internal connection. The vital problem lies, however, in the circumstance that, at least as far as law-like connections are concerned, the relationship between the datum of an invariable regularity and the existence of a universal law consists in the fact that the former merely supports the assumption of the latter as a hypothesis. It is on two accounts that a statistical regularity does not necessitate a corresponding law-like connection: First the existence of the former does not strictly guarantee the existence of any law-like connection at all. The very idea that in the entire history of the universe some type of event is always followed by some other type of event and that this circumstance is due to sheer coincidence is not inconsistent. Second, even if in some particular realm, irrespective of how large it is, an invariable regularity of co-occurrence between items of type T1 and type T2 is in fact the outcome of some law, it does not follow that the comprehensive law licensing extrapolation with respect to some realm $\mathrm{R}$ pertains to the types $\mathrm{T} 1$ and $\mathrm{T} 2$ themselves; the supposition that only a rule saying that an item of $\mathrm{T} 2$ occurs whenever an item of type T1 exists which does not belong to $\mathrm{R}$ is applicable to the extended realm is not logically incompatible with the given data. It might in fact hold good that the circumstance that the realm $\mathrm{R}$ constitutes an exception to the original regularity is itself the result of a deeper more universal law. But the crucial fact is that under those circumstances the comprehensive law could not be described in terms of T1 and T2 alone. The situation appears to be analogous even in non-empirical areas. On the one hand it seems that universal compliance with the regularity formulated in Goldbach's conjecture in every realm that has been considered is suited to trigger the intuitive supposition that the regularity should be the outcome of some mathematical fact undiscovered up to now. On the other hand it appears that such data cannot strictly guarantee that there is such a fact. But even the supposition that the circumstance that all even numbers equal the sum of two primes in realms under consideration are the outcome of some underlying general principle of arithmetic would not rule out the possibility that the underlying principle entails a theorem of the form 
If $\mathrm{x}$ is an even number and either greater than $\mathrm{m}$ and smaller than $\mathrm{n}$ or greater than $\mathrm{o}$ and smaller than $\mathrm{p}$ (or ...) then $\mathrm{x}$ equals the sum of two prime numbers. and not a theorem of the form

If $\mathrm{x}$ is an even number which is greater than 2 then $\mathrm{x}$ equals the number of two prime numbers.

Therefore a major deficiency of Dharmakīti's solution of the problem posed by the sadvitiyaprayoga might lie in the circumstance that the kind of connection between statistical regularities and assumptions of internal, in particular law-like, connections was not adequately identified. To be sure, if examples are considered, such as

If Jack has an oak in his garden then Jack has a tree in his garden.

the truth of the corresponding universal proposition

Everybody who has an oak in his garden has a tree in his garden.

appears to be beyond any reasonable doubt. Here it seems odd to suppose that the universal statement might require some specification relating to some specific realm of objects. But with respect to such cases it appears equally odd to suppose that the truth of the universal statement is licensed by any principle of extrapolation. The truth of the proposition expressed by

Everybody living in England who has an oak in his garden has a tree in his garden.

is surely entailed by the universal sentence but none of the sentences under consideration is such that its truth enhances the probability of truth with respect to any other.

In Oetke (1996) it had been intimated that the doctrine of Trairüpya contains ingredients which possess a certain 'methodological' function. This holds good in particular for the second and third conditions of trairüpya whose satisfaction guarantees that in the realm of objects apart from the substratum of inference, the pakșa, the properties functioning as probans and probandum within an inferential argument are not only instantiated together but are also related such that the latter occurs whenever the former occurs without any exception. The methodological function of those ingredients can be seen in their ability of providing support for 'default-rules' of inference whose general character could be roughly described by

If $\mathrm{p}$ exhibits $\mathrm{H}$ and no evidence exists for assuming that $\mathrm{p}$ exhibits the quality of not being $\mathrm{S}$ then it is to be supposed that $\mathrm{p}$ exhibits $\mathrm{S}$

This means that the conditions which guarantee invariable compliance with a regularity in the realm of objects which are different from the pakșa justify the acceptance of an inference rule pertaining to the pakssa itself. Against the background of the preceding considerations it follows that the inference rules of the above specified sort possess the status of defaults in two different respects. On the one hand they exhibit a, so to speak, internal default character inasmuch as they license the derivation of a conclusion only under the proviso that no evidence supporting a 
contrary conclusion exists. On the other hand, they possess a default character in an external respect inasmuch as the methodological principles which license their approval can provide merely support without making their acceptance compelling. In principle extension of experience can diminish or even destroy the basis of their acceptability. It is not unimportant to notice that the 'external' default character would persist even if it were supposed that the pertinent inference rules do not exhibit the character of defaults in internal respect. This means that their general form should not be described in the above manner but rather by:

If $\mathrm{p}$ exhibits $\mathrm{H}$ then it is to be supposed that $\mathrm{p}$ exhibits $\mathrm{S}$

The default character in external respect is imperative as long as one supposes that their justification should rely on the above specified extrapolation principle. It appears patent that with respect to examples, such as

If $\mathrm{p}$ exhibits the quality of an oak it is to be supposed that it exhibits the quality of a tree

the situation is fundamentally different. However, the reason for this deviance should not be seen in the circumstance that in the latter type of cases-a type which plays equally a prominent role in Dharmakīrti's doctrine of inference and proofthe extrapolation principle possesses greater strength in so far as compliance with a regularity in the realm of objects different from the pakșa provides compelling support for compliance with the same regularity in a different realm. Rather one should say that compliance with an analogous regularity in a different realm does not play the role of providing any support at all. Any basis which might license the acceptance of an inference rule with respect to some particular instance is equally a basis which licenses the acceptance of the supposition of a corresponding regularity in all other instances. Therefore compliance with the second and third condition of trairūpya possess no substantial function in the present context. Invoking satisfaction with those requirements could at most fulfil a role of control in special intricate cases. As sometimes logical relations between concepts are not immediately obvious, one might find it useful to examine whether certain examples which are known to exhibit a particular quality equally possess some other quality and whether instances can be found which force one to assume that one quality occurs and some other not. But this function is fundamentally different from that of providing a basis justifying the hypothesis of compliance with a regularity in some particular case.

It is far from certain that Dharmakīti has provided an adequate account of the difference between the two types considered above and that he has provided an acceptable explanation of the ground that bestows validity on inferences in the second type of cases. The issue which is at stake affects the reliability of metaphysical reasoning because the previous considerations imply that as long as inference rules employed in this context essentially rely on an extrapolation principle outcomes of metaphysical reasoning can never claim to be absolutely reliable. Maybe the Western tradition has achieved decisive superiority in so far as it has subjected the nature of metaphysical reasoning to a critical examination. 
Even if it were supposed, however, that Dharmakīrti or certain other representatives of the later tradition of thought have offered satisfactory answers to the questions and problems that are alluded to in the preceding exposition, the inventor (s) of the sadvitiyaprayoga ought to be credited with the merit of having brought into view a most significant philosophical issue. If it should be true that the topic had been raised by proponents of materialistic views the depreciation of materialism in India would be definitely reprehensible.

\section{References}

Franco, E. (2012). A Note on the Sadvitīyaprayoga. Journal of Indian Philosophy, 40, 219-224.

Oetke, C. (1996). Ancient Indian logic as a theory of non-monotonic reasoning. Journal of Indian Philosophy, 24(5), 447-539. 